2002s-15

\title{
Entry Preventing Locations Under Incomplete Information
}

\author{
Marcel Boyer, Philippe Mahenc, \\ Michel Moreaux
}

\begin{tabular}{c}
\hline Série Scientifique \\
Scientific Series
\end{tabular}

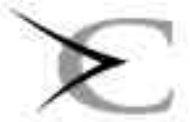

CIRANC

Montréal

Février 2002 


\section{CIRANO}

Le CIRANO est un organisme sans but lucratif constitué en vertu de la Loi des compagnies du Québec. Le financement de son infrastructure et de ses activités de recherche provient des cotisations de ses organisationsmembres, d'une subvention d'infrastructure du ministère de la Recherche, de la Science et de la Technologie, de même que des subventions et mandats obtenus par ses équipes de recherche.

CIRANO is a private non-profit organization incorporated under the Québec Companies Act. Its infrastructure and research activities are funded through fees paid by member organizations, an infrastructure grant from the Ministère de la Recherche, de la Science et de la Technologie, and grants and research mandates obtained by its research teams.

\section{Les organisations-partenaires / The Partner Organizations}

-École des Hautes Études Commerciales

-École Polytechnique de Montréal

-Université Concordia

-Université de Montréal

-Université du Québec à Montréal

-Université Laval

-Université McGill

-Ministère des Finances du Québec

-MRST

-Alcan inc.

- AXA Canada

-Banque du Canada

-Banque Laurentienne du Canada

- Banque Nationale du Canada

- Banque Royale du Canada

- Bell Canada

- Bombardier

-Bourse de Montréal

-Développement des ressources humaines Canada (DRHC)

-Fédération des caisses Desjardins du Québec

-Hydro-Québec

-Industrie Canada

-Pratt \& Whitney Canada Inc.

-Raymond Chabot Grant Thornton

-Ville de Montréal

(C) 2002 Marcel Boyer, Philippe Mahenc et Michel Moreaux. Tous droits réservés. All rights reserved. Reproduction partielle permise avec citation du document source, incluant la notice $($ )

Short sections may be quoted without explicit permission, if full credit, including (C) notice, is given to the source.

Les cahiers de la série scientifique (CS) visent à rendre accessibles des résultats de recherche effectuée au CIRANO afin de susciter échanges et commentaires. Ces cahiers sont écrits dans le style des publications scientifiques. Les idées et les opinions émises sont sous l'unique responsabilité des auteurs et ne représentent pas nécessairement les positions du CIRANO ou de ses partenaires.

This paper presents research carried out at CIRANO and aims at encouraging discussion and comment. The observations and viewpoints expressed are the sole responsibility of the authors. They do not necessarily represent positions of CIRANO or its partners.

\section{ISSN 1198-8177}




\title{
Entry Preventing Locations Under Incomplete Information ${ }^{* \dagger}$
}

\author{
Marcel Boyer, Philippe Mahenc ${ }^{\S}$ and Michel Moreaux ${ }^{* *}$
}

Revised: October 2001

Résumé / Abstract

Nous montrons qu'en présence d'information asymétrique sur les coûts, les stratégies de localisation limite, c'est-à-dire les distorsions dans les localisations permettant à la firme établie d'empêcher l'entrée, résultent non seulement de l'avantage coût de la firme établie mais aussi des croyances de l'entrant concernant cet avantage. La localisation au centre du marché peut dissuader d'entrer, si l'on se trouve en information incomplète et en présence d'une firme établie encourant un coût élevé. Cette même firme accepterait l'entrée en information complète. De plus, une firme établie, encourant un coût faible dissuadant l'entrée à cette localisation en information complète, aurait intérêt à accepter l'entrée si elle se trouvait en information incomplète.

We show that, under asymmetric information about costs, limit location strategies, that is distortions in pre-entry locations created by the entrant's inference about the incumbent's cost advantage which prevent entry, emerge not only as the result of the incumbent's cost advantage but also as the result of the entrant's beliefs concerning this advantage. The location at the market center may deter entry under incomplete information for a high cost incumbent who would accommodate entry under complete information; moreover, a low cost incumbent deterring entry at that location under complete information may be better off accommodating entry under incomplete information.

\footnotetext{
* Corresponding author - Philippe Mahenc, JEREM, Département de Sciences Économiques, Université de Perpignan, 52, Avenue de Villeneuve, 66860 Perpignan, Cedex France.

$\dagger$ We thank two anonymous referees and the editor Simon Anderson for very helpful comments on a first version of this paper. Financial support from SSHRCC (Canada) and INR.A (France) is gratefully acknowledged.

* Université de Montréal and CIRANO.

$\S$ JEREM, Université de Perpignan.

*** Institut universitaire de France - Université de Toulouse 1, IDEI and LEERNA-INRA.
} 


\section{Introduction}

The choice of product location is crucial for a firm facing a threat of potential entry. Empirical investigations have provided evidence that incumbent firms use product specification and/or product proliferation to deter entry (see Smiley, 1988). In reaction to Schmalensee's (1978) claim that an incumbent monopolist could use product proliferation to deter entry, Bonanno (1987) exhibits cases where the incumbent's choice of particular locations, that is product specification as opposed to product proliferation, is a more profitable strategy to deter entry: the number of stores opened by the incumbent facing a threat of entry is the same as the number of stores opened by a protected monopolist but the locations of these stores turn out to be different. Addressing the problem of the credibility of entry deterrence, Judd (1985) shows that an incumbent with low exit costs fails to deter entry by crowding the product spectrum. Donnenfeld and Weber (1995) highlight that quality specification may also be used as an entry-deterring device in an industry with vertically differentiated products.

In these models, information is always assumed to be complete, ${ }^{1}$ thus cannot play any role in discouraging potential entrants. This may sound surprising as the bulk of the related literature on price as a barrier to entry, originating in the limit-pricing model of Milgrom and Roberts (1982), assumes uncertainty over firm types and therefore asymmetric information between firms. ${ }^{2}$ Milgrom and Roberts modeled the problem of entry deterrence as a game of incomplete information in which limit-pricing behavior emerges endogenously in equilibrium: when a potential entrant does not know the incumbent's marginal cost, the latter may discourage entry by charging a pre-entry price below her monopoly price in order to signal that she is a low cost incumbent, hence a potentially aggressive competitor if entry occurs.

In the present paper, we consider a model of competition in differentiated products under incomplete information unfolding as follows: first, the incumbent selects a particular location for her product (from now on, the product choice on a linear market of differentiated products will generally be referred to by the usual term "location"); second, a potential entrant observes this choice and decides to enter if he can make positive profits (net of fixed cost); third, if entry occurs

\footnotetext{
${ }^{1}$ Information may be imperfect but all firms have the same information and face the same uncertainty.

${ }^{2}$ See also Bagwell and Ramey (1988), Harrington (1987), Overgaard (1994).
} 
the firms compete in prices, otherwise the incumbent monopolizes the market. This sequence of moves is reminiscent of the location-price duopoly setup initially investigated by Hotelling (1929) and more recently by d'Aspremont, Gabszewicz and Thisse (1979) in the uniform mill pricing case and by Lederer and Hurter (1986) in the delivered pricing case.

More formally, we investigate the following asymmetric information location model. The potential entrant is assumed to be imperfectly informed about some characteristic of the established firm which is relevant for his post-entry profit. In our model this characteristic is the incumbent's production cost which we assume to be her private information. We assume that the incumbent is at least as efficient as the entrant, that is, her unit production cost is lower than or the same as the entrant's and the latter does not know whether he faces a more efficient (strong) competitor or a similarly efficient (weak) one. We concentrate on spatial differentiation and assume that firms choose their products or equivalently their locations sequentially before they simultaneously compete in prices. If the entrant decides to enter, the true cost of the incumbent is revealed before the price competition stage. ${ }^{3}$

In order to avoid trivialities, we focus on the case in which, under complete information, the more efficient incumbent would blockade entry at the market center whereas the less efficient incumbent would accommodate entry; ${ }^{4}$ in other words, the fixed cost of the potential entrant is neither too small (so that the entrant would always enter) nor too large (so that the entrant would never enter). Recall that in our model the incumbent can credibly commit to her preentry location choice. Moreover, our analysis shows that entry deterring behavior emerges not only as the result of the incumbent's cost advantage, that is, the large fixed cost of entry and the difference in production costs as in the standard complete information literature, but also as the result of the entrant's beliefs concerning this cost advantage. Expectations of positive profits may be self-fulfilling in a context of incomplete information. Thus an incumbent may

\footnotetext{
${ }^{3}$ This assumption has been rather standard since the seminal work of Milgrom and Roberts (1982). It could be relaxed at the cost of more intricate analysis. It has the advantage in the present context of allowing us to concentrate on the product specification or location decisions.

${ }^{4}$ Bain (1956) suggested that an incumbent facing potential entry could follow one of three strategies: she blockades entry if, by choosing the strategy which would be chosen without the threat of entry, entry is prevented. When entry cannot be blockaded, she deters entry if, by altering her strategy, she successfully impedes entry. Finally, the incumbent accommodates entry if she finds more profitable to let a competitor enter the market than to erect costly barriers.
} 
rationally accommodate entry because she is not believed to be sufficiently strong to blockade entry even if she is indeed strong enough when properly identified.

Our results can be summarized as follows. Suppose there is a one-address store in a linear city, the manager of which is endowed with private information about her opportunity cost of being established in the city. A potential entrant may use the incumbent's location as a signal of her private information. From the complete information analysis of Ziss (1993), a simple intuitive analysis could suggest that the city or market center location demonstrates entry blockading strength, in which case the potential rival would be worse off entering, while a location away from the center is 'a sign of allegiance' indicating that the incumbent is weak and ready to accommodate entry. However, the analysis of the incentives for entry prevention under the assumption of asymmetric information raises issues that are more subtle than these intuitions may suggest. The first intuition ignores the weak incumbent's incentive to mimic her strong counterpart when the potential entrant is rather persuaded ex ante that the incumbent is strong. We demonstrate that pooling at the city center may emerge in equilibrium, thus the city center may be used as a limit location by a weak incumbent. The second intuition ignores the strong incumbent's incentive to engage in costly signaling to prove her strength. In such a case, a location away from the center, far from being 'a sign of allegiance', may be either a credible signal of strength that is too costly to be mimicked by a weak incumbent or a pooling location chosen to relax post-entry competition when revealing her true strength is impossible or too costly for the strong incumbent.

The intuition behind these results rests on the pre-entry location becoming a signal regarding the incumbent's unit cost. If the entrant is sufficiently pessimistic, believing rather strongly that the incumbent is strong, the market center emerges as an entry deterring (pooling) equilibrium for the high cost incumbent because information is not disclosed in equilibrium: the high cost incumbent finds it profitable to mimic her low cost counterpart and therefore the market center is in this case the only plausible equilibrium location. In equilibrium, the potential entrant remains uninformed regarding his competitor's cost and stays out, whereas he would enter and compete against a high cost incumbent under full information. The low cost incumbent remains at the market center, her full information entry blockading equilibrium location. However, if 
the entrant is sufficiently optimistic, believing rather strongly that the incumbent is weak, he enters the market whatever the incumbent's location and true cost. Since the incumbent fails to prevent entry even if she is in fact more efficient than the entrant, locating at the market center exacerbates the level of post-entry competition. Thus, when the entrant is sufficiently optimistic, not only is the market center no longer an entry blockading pooling equilibrium location but it cannot be an equilibrium location for the incumbent whatever her type. The low cost incumbent finds profitable in this case to locate away from the market center and to accommodate entry. Two cases may be distinguished depending on technological characteristics, that is the fixed and variable costs. Either separation of the types is possible and the low-cost incumbent discloses her true cost by locating in an area away from the market center where the high-cost incumbent wouldn't locate, or separation of the types is not possible and a pooling equilibrium emerges away from the market center. In both cases the low-cost incumbent moves away from the market center to benefit from a higher degree of product differentiation, hence a less intensive post-entry competition. It is worth noting that these conclusions are fairly robust to the type of competition prevailing in the second stage of the game. We illustrate this robustness in the classical mill pricing competition framework and in the delivered pricing competition framework.

When location is interpreted as product characteristics, there is also evidence of firms using limit location strategies to deter entry or, by contrast, locating off the mainstream characteristics to signal efficiency. Consider for instance a variety of wine such as "Côtes du Roussillon" that requires blending two main vines, Carignan and Grenache, in precise proportions to get the "Appellation". Most of the wine growers in the Roussillon region choose to blend the aforementioned vines accordingly to be identified as "Côtes du Roussillon" although they face different production costs. This can be interpreted as a pooling strategy deterring entry on the market for local wines. However, some wine growers are better off producing a wine from a single vine, hence spurning the mainstream "Appellation". Clearly, such a choice could not be afforded by inefficient producers and therefore can be interpreted as a separating strategy.

The paper is organized as follows. We present the basic model in section 2 . We devote section 3 to the characterization of the perfect Bayesian location equilibria, both the separating 
and the pooling ones. The uniform mill pricing case and the delivered pricing case are analyzed in sections 4 and 5 . We then conclude in section 6 .

\section{The Model}

We consider a continuum of consumers distributed on a segment $[0, L], L<\infty$, according to a continuously twice differentiable, symmetric and strictly positive density function $g: g(x)=$ $g(L-x)>0$ for all $x \in[0, L]$ with a maximum at $x=L / 2$. Each consumer buys one unit of the good, provided that its price is not higher than some reservation value $r$, the same for all consumers. Since the firms are assumed to sell an homogeneous product, a consumer will buy from the firm that quotes the lowest full price, either the uniform mill price plus the transportation cost as in Hotelling (1929) or a delivered price as in Hoover (1937).

An incumbent, firm 1, and a potential entrant, firm 2, are involved in a two stage game. The firms move sequentially in the first stage, the incumbent as the first mover choosing her location $x_{1}$ and the entrant making two simultaneous decisions after observing firm's 1 location, to enter the market or not and upon entry to locate his single plant at $x_{2}$, where $x_{i}$ denotes the location of firm $i$ from 0 . There is a fixed sunk cost of entry and locations are irreversible. In the second stage of the game the firms compete in prices, for instance in uniform mill prices or in delivered prices. Using the results of d'Aspremont, Gabszewicz and Thisse (1979), Champsaur and Rochet (1988) and Bester (1992) for the first case, and Lederer and Hurter (1986) for the second case, we will make sufficient assumptions on $r, g$ and the variable production and transportation costs to ensure that there exists a unique pure strategy Nash equilibrium in the second stage subgame, which is of course the interesting case to look at.

The two stage game captures the idea that investment decisions such as location choices are long term decisions, while the relatively flexible price decisions are short term decisions. As long as the choice of product characteristics have not been made, the potential entrant ignores the incumbent's cost. However the process of price competition is supposed to convey information very quickly. Thus, if it enters, firm 2 learns firm 1's characteristics, relevant to the post-entry profits of both firms, before the price competition takes place in stage 2. Hence, as in Milgrom 
and Robert's (1982) model of limit pricing, the second stage competition occurs under complete information. The firms, assumed to be risk neutral, maximize their expected profit at the first stage.

If it enters, firm 2 incurs a constant average variable cost $c$ and a fixed cost $f$. The incumbent only bears a variable cost and is assumed to be either strong or weak. We will refer to firm 1 with constant average variable costs 0 and $c$ as the low cost (strong) and high cost (weak) types respectively. Let $T=\{t \mid t \in\{h, \ell\}\}$ be the set of firm 1's types, $h$ denoting the high cost type and $\ell$ the low cost type, and let $\mu_{t}^{0}$ be the probability of type $t, t \in T$; to simplify the notation, we will write $\mu^{0}$ for $\mu_{\ell}^{0}$. Since we assume that the density $g(x)$ is symmetric and single peaked at $L / 2$, we may restrict our attention to $x_{1} \in[0, L / 2]$. We assume that the profits over variable costs, either production costs or production and transportation costs according to which kind of pricing prevails at the final stage of the game, of a monopoly by firm 1 of type $t$ located at $x_{1}$, denoted by $\Pi_{1}^{M}\left(x_{1}, t\right)$, is increasing in $x_{1}$. Firm 1 , knowing its type, chooses a location $x_{1}$. Firm 2 observing $x_{1}$ responds with a choice of location $x_{2}$. In the context of our model, firm 2 , if it enters, will locate to the right of the market center; hence, we may restrict our attention to $x_{2} \in[L / 2, L] \cup\{N E\}$ where $N E$ means that firm 2 has chosen not to enter.

The objective being to study situations in which the incumbent may consider locations different from her complete information locations, we concentrate on the more interesting context in which, under complete information, entry is blockaded by a low cost incumbent but accommodated by a high cost incumbent, hence occurs with probability $1-\mu^{0}$. Under the assumption of asymmetric information, the location chosen by the incumbent becomes a signal of her unit cost and may therefore influence the entrant's decision.

Under full information a location may be entry blockading for an incumbent only if the potential entrant incurs a sufficiently high fixed cost $f$. We assume that $f \in(\underline{f}, \bar{f})$. The lower value $\underline{f}$ is the upper bound of the fixed cost allowing the entrant to enter the market whatever the location and type of firm 1 . If $f \leq \underline{f}$ then whatever her location and whatever her type, an incumbent cannot deter entry and both types accommodate entry in a full information equilibrium: facing the low cost incumbent, the entrant locates further away from the market 
center so that products are more differentiated than when firm 1 is a high cost incumbent. ${ }^{5}$ The higher value $\bar{f}$ is the lower bound of the fixed cost values allowing the high cost incumbent to blockade entry by simply locating at the market center. This is then the optimal location of both types. In addition, this location also minimizes the maximum attainable gross profit of a potential entrant. Hence for values higher than $\bar{f}$, entry is blockaded. When $f \in(\underline{f}, \bar{f})$, the weaker incumbent can no longer blockade entry under full information. Realizing this, she locates away from the market center and firm 2 enters and locates also away from the market center in order to soften price competition. The low cost incumbent can still blockade entry by locating at the market center. Hence, for $f$ in this interval, entry is accommodated by the high cost incumbent whereas it is blockaded by the low cost incumbent under full information.

A pure strategy of firm 1 is a decision function $x_{1}(t), t \in T$, giving the location of firm 1 as a function of its type. A pure strategy of firm 2 is a decision function $x_{2}\left(x_{1}\right)$ giving either the location of firm 2 as a function of the firm 1's location if firm 2 decides to enter or taking the value $N E$ if firm 2 chooses not to enter. Let $\Pi_{i}\left(x_{1}, x_{2}, t\right), i=1,2$ be the profit of firm $i$ when firm 1 is of type $t$ and locations are $x_{1}$ and $x_{2}$. We assume that, for $x_{1} \in[0, L / 2]$ and $x_{2} \in[L / 2, L]$, the profits $\Pi_{1}$ and $\Pi_{2}$ are continuous in $\left(x_{1}, x_{2}\right), \Pi_{1}$ is increasing in $x_{1}$ and $\Pi_{2}$ is strictly concave in $x_{2}$. Clearly, $\Pi_{1}$ jumps upwards when firm 2 switches from some location $x_{2} \in[L / 2, L]$ to $x_{2}=N E$. From the concavity of $\Pi_{2}$ in $x_{2}$, firm 2 never randomizes. To simplify the notation, let us write $\mu$ as the posterior probability with which firm 2 believes that firm 1 is of the low cost type. We denote by $\tilde{x}_{2}\left(x_{1}, \mu\right)$ the best response of firm 2 to $x_{1}$ given $\mu$ taken as a parameter, that is $\tilde{x}_{2}\left(x_{1}, \mu\right)$ maximizes $\mu \Pi_{2}\left(x_{1}, x_{2}, \ell\right)+(1-\mu) \Pi_{2}\left(x_{1}, x_{2}, h\right)$. The location $\tilde{x}_{2}$ is continuous in $\left(x_{1}, \mu\right)$ as long as firm 2 enters the market.

We assume that $\partial \Pi_{2} / \partial x_{2} \partial x_{1}>0$ implying that $\tilde{x}_{2}\left(x_{1}, \mu\right)$ is non decreasing in $x_{1}:{ }^{6}$ the marginal profitability for firm 2 of a larger $x_{2}$ increases as firm 1 locates closer to the center since price competition is relaxed when firm 2 chooses a more differentiated product. Moreover $\tilde{x}_{2}\left(x_{1}, \mu\right)$ is a non-decreasing function of $\mu$ since the entrant is better off increasing differentiation when he puts more probability on the low cost type of firm 1. More generally, we denote by

\footnotetext{
${ }^{5}$ The analysis is then similar to the case with no fixed cost studied in Boyer, Laffont, Mahenc and Moreaux (1994, 1995).

${ }^{6}$ More precisely, $\tilde{x}_{2}\left(x_{1}, \mu\right)$ is increasing in $x_{1}$ except if it is already at $L$.
} 
$\mu_{t}\left(x_{1}\right)$ the probability assigned by firm 2 to type $t$ given the observed location $x_{1}$. In order to capture the idea that it is more costly for the high cost type to locate close to the center, we assume the following single crossing property:

$$
\forall x_{1} \in I_{1}, \forall x_{2} \in[L / 2, L], \text { then } \frac{\partial \Pi_{1}\left(x_{1}, x_{2}, \ell\right)}{\partial x_{1}}>\frac{\partial \Pi_{1}\left(x_{1}, x_{2}, h\right)}{\partial x_{1}} .
$$

The above model specification is relatively standard in location theory except for the fact that it is the first location model to consider the entry preventing role of fixed costs under incomplete information. The specific modeling strategy used here can be justified as follows. The second stage competition is assumed to be a Bertrand-like competition with the necessary assumptions to guarantee the existence of a unique equilibrium. We can then concentrate on the role of fixed sunk costs in determining location choices. The particular incomplete information structure considered here, namely an informed incumbent at least as efficient as the uninformed entrant, corresponds to many observed situations such as those in which an incumbent firm may have acquired or not a cost advantage through learning or experience. Because of the information structure and the sequencing of moves, the location chosen by an established firm becomes a signal regarding its costs, that is the effect of learning and experience. This signal may be used by the second mover to infer the type of the first mover, that is, whether or not firm 1 has acquired a cost advantage, a critical factor in the second stage competition. This is well understood by firm 1 who may attempt to manipulate the signal through its location choice. The other elements of the model are basically simplifying assumptions or standard features of location models.

We are looking for a perfect Bayesian equilibrium (PBE) which is the natural equilibrium concept in the present context. A PBE is a pair of decisions $x_{1}^{*}(t), t=h, \ell$, and $x_{2}^{*}\left(x_{1}\right), x_{1} \in[0, L / 2]$, and posteriors $\mu_{t}^{*}\left(x_{1}\right)$ such that: (i) for $t=h, \ell: \quad x_{1}^{*}(t) \in \underset{x_{1} \in I_{1}}{\arg \max } \Pi_{1}\left(x_{1}, \tilde{x}_{2}\left(x_{1}^{*}, \mu_{t}^{*}\left(x_{1}\right)\right), t\right)$, that is, the incumbent of type $t$ maximizes her profit given the strategy of firm 2; (ii) for any $x_{1} \in[0, L / 2]: x_{2}^{*}\left(x_{1}\right)=\tilde{x}_{2}\left(x_{1}^{*}, \mu_{t}^{*}\left(x_{1}^{*}\right)\right)$, that is, the potential entrant maximizes his expected profit for any decision $x_{1}$ taken by firm 1 , given his posterior belief function $\mu_{t}^{*}\left(x_{1}\right)$; (iii) for any $x_{1} \in[0, L / 2]$, the posterior probabilities $\mu_{t}^{*}\left(x_{1}\right)$ are obtained from the prior $\mu^{0}$ and firm 1 strategy via Bayes' rule if Bayes' rule can be applied, that is, if $x_{1} \in\left\{x_{1}^{*}(t) \mid t \in T\right\}$, whereas they are arbitrary for out-of-equilibrium locations $x_{1}$. 


\section{The Location Equilibria}

\subsection{The reduced profit function}

In order to characterize more easily the different PBE's, it is convenient to work with the reduced form of firm 1's profit function, denoted by $\hat{\Pi}_{1}\left(x_{1}, \mu, t\right), t=h, \ell$. This is the profit the type $t$ of firm 1 would earn when it locates at $x_{1}$ and firm 2 responds optimally believing that firm 1 is of the low cost type with probability $\mu$. This probability $\mu$ is taken here as a parameter. Hence:

$$
\hat{\Pi}_{1}\left(x_{1}, \mu, t\right)=\Pi_{1}\left(x_{1}, \tilde{x}_{2}\left(x_{1}, \mu\right), t\right), \quad t=h, \ell .
$$

If firm 2 had no fixed cost to incur for entering the market, the reduced function $\hat{\Pi}_{1}$ would be a continuous function in $x_{1}$ and $\mu$ since firm 2 would always enter the market at a location which would be a continuous function of firm 1's location and the belief $\mu .^{7}$

We assume that, when the fixed cost is $0, \hat{\Pi}_{1}\left(x_{1}, \mu, t\right)$ is strictly concave in $x_{1}$ on $[0, L / 2]$ for any $t$ and $\mu$ and increasing in $\mu$, as depicted in Figure 1 . This implies that both types of firm 1 prefer the best response of firm 2 when the latter believes that firm 1 is more likely of the low cost type. ${ }^{8}$ The idea is that firm 1 prefers more product differentiation from firm 2 and this happens when firm 2 considers more likely that firm 1 is of the low cost type.

Note that, if $t=\ell$, then the profit function of firm 1 rightly identified as a low cost firm is given by $\hat{\Pi}_{1}\left(x_{1}, 1, \ell\right)$, that is the upper contour of the family of curves drawn in Figure 1; whereas if $t=h$, then the profit function of firm 1 rightly identified as a high cost firm is given by $\hat{\Pi}_{1}\left(x_{1}, 0, h\right)$, that is the lower contour curve. Assuming that under full information the weaker incumbent locates away from the market center $L / 2$ means that the value of $x_{1}$ at which $\hat{\Pi}_{1}\left(x_{1}, 1, h\right)$ is maximized, $x_{1}^{m}(1, h)$, is strictly lower than $L / 2$ as shown in Figure 1 for $t=h$.

\footnotetext{
${ }^{7}$ Technically, $\tilde{x}_{2}\left(x_{1}, \mu\right)$, the best response of firm 2 , would take values in $[L / 2, L]$ instead of $[L / 2, L] \cup\{N E\}$ and would be continuous in both $x_{1}$ and $\mu$.

${ }^{8}$ This is an implication of $\Pi_{1}$ increasing in $x_{2}$ and $\tilde{x}_{2}\left(x_{1}, \mu\right)$ increasing in $\mu$.
} 
FIGURE 1

The reduced profit functions: the case $f=0$



Remember that we are assuming that under full information entry is accommodated by the high cost incumbent whereas entry is blockaded by the low cost incumbent. It means first that, if firm 2 believes that it is fighting a low cost firm 1 , there exists some location $\bar{x}_{1}<L / 2$ such that by choosing a location $x_{1} \in\left[\bar{x}_{1}, L / 2\right]$, firm 1 deters entry whatever its true type; second that, if firm 2 believes it is facing a high cost firm 1, whatever the true cost of firm 1 and its location, the incumbent cannot prevent the entry of firm 2 . Hence for $\mu$ sufficiently low, the functions $\hat{\Pi}_{1}\left(x_{1}, \mu, t\right)$ are like those of figure 1 and for $\mu$ sufficiently high, the exists some limit location $\bar{x}_{1}(\mu)$ such that $x_{1} \in\left[\bar{x}_{1}(\mu), L / 2\right]$ prevents entry. In this last case, depicted on Figure 2 , entry is prevented for $x_{1} \geq \bar{x}_{1}(\mu)$ and $\hat{\Pi}_{1}\left(x_{1}, \mu, t\right)$ is equal to the monopoly profit of firm 1 of type $\mathrm{t}$ located at $x_{1}$, which does not depend upon $\mu$ and is denoted by $\Pi_{1}^{M}\left(x_{1}, t\right)$. Under our assumptions $\bar{x}_{1}(\mu)$ is a decreasing function of $\mu$. Note that there must exist some critical value $\bar{\mu}$ of $\mu$ such that firm 1 can deter entry or not according to whether $\mu$ is higher or lower than $\bar{\mu}$, 
so that $\lim _{\mu \downarrow \bar{\mu}} \bar{x}_{1}(\mu)=L / 2$. Similarly, it will be useful to denote by $\bar{\mu}\left(x_{1}\right)$ the minimum value of $\mu$ for which entry is deterred given $x_{1}$.

\section{FIGURE 2}

The reduced profit functions: the case $f>0$

$\left(0<\mu^{\prime}<\bar{\mu}<\mu<1\right)$

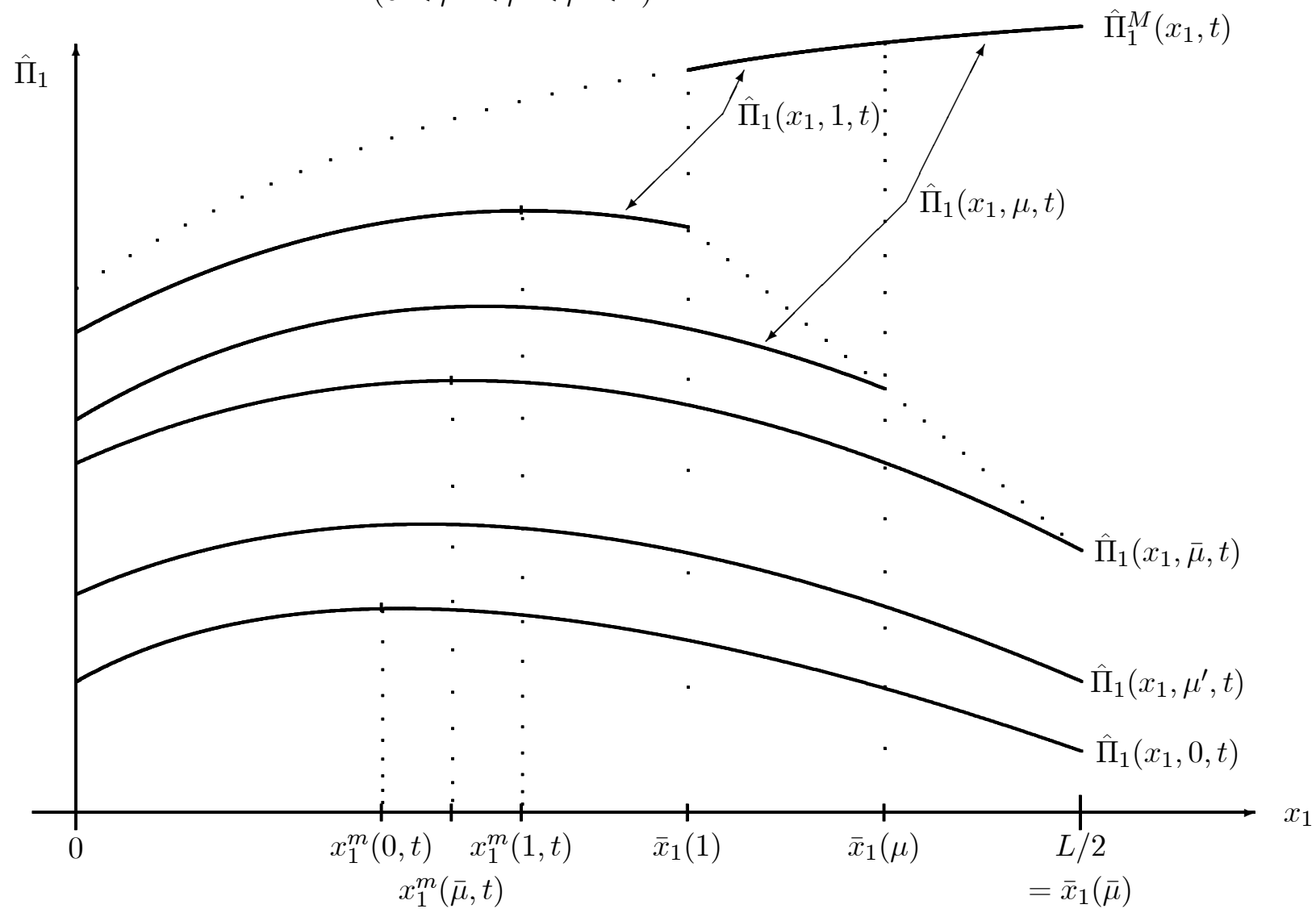

In what follows, we will denote by $x_{1}^{m}(\mu, t)$ the location at which the reduced profit function $\hat{\Pi}_{1}\left(x_{1}, \mu, t\right)$ is maximized either over the interval $\left[0, \bar{x}_{1}(\mu)\right]$ if $\bar{x}_{1}(\mu)<L / 2$ (that is if $\mu<\bar{\mu}$ ) or over the interval $[0, L / 2]$ otherwise.

\subsection{Pooling equilibria}

Let us first examine the pooling equilibria. Suppose that some location $x_{1}^{\prime}$ is a pooling equilibrium location. Since in a pure strategy pooling equilibrium, both types of firm 1 choose the same location, then by observing $x_{1}^{\prime}$, firm 2 obtains no additional information and the priors and 
posteriors are the same. Hence the equilibrium profit of firm 1 of type $t$ is given by $\hat{\Pi}_{1}\left(x_{1}^{\prime}, \mu^{0}, t\right)$ where $\mu^{0}$ is the prior probability that firm 1 is of the low cost type. In order to check if this location can be sustained by some out-of-equilibrium posteriors, we can simply examine the most detrimental posteriors for firm 1's profits, that is the following: observing $x_{1}^{\prime \prime} \neq x_{1}^{\prime}$, firm 2 believes with certainty that firm 1 is of the high cost type generating profits $\hat{\Pi}_{1}\left(x_{1}, 0, t\right)$. If for some type $t$ we have $\hat{\Pi}_{1}\left(x_{1}^{\prime \prime}, 0, t\right)>\hat{\Pi}_{1}\left(x_{1}^{\prime}, \mu^{0}, t\right)$, then type $t$ would deviate from $x_{1}^{\prime}$. However, if for both types $\hat{\Pi}_{1}\left(x_{1}^{\prime \prime}, 0, t\right) \leq \hat{\Pi}_{1}\left(x_{1}^{\prime}, \mu^{0}, t\right)$, then there exists some probability $\tilde{\mu}^{\prime \prime}$ such that for any $\mu^{\prime \prime}<\tilde{\mu}^{\prime \prime}$, we have $\hat{\Pi}_{1}\left(x_{1}^{\prime \prime}, \mu^{\prime \prime}, t\right) \leq \hat{\Pi}_{1}\left(x_{1}^{\prime}, \mu^{0}, t\right)$ for both $t=h, \ell$. Any such posterior $\mu^{\prime \prime}$ sustains $x_{1}^{\prime}$ as a pooling equilibrium.

Proposition 1: A location $x_{1}^{*}$ may be a pooling equilibrium location for the prior $\mu^{0}$ if and only if for any $x_{1} \neq x_{1}^{*}$, we have $\hat{\Pi}_{1}\left(x_{1}, 0, t\right) \leq \hat{\Pi}_{1}\left(x_{1}^{*}, \mu^{0}, t\right)$.

Not all locations can be pooling equilibrium locations as illustrated in Figure 3. Consider first the low cost type and let $b$ be the location at which $\hat{\Pi}_{1}(b, 1, \ell)=\max _{x_{1}} \hat{\Pi}_{1}\left(x_{1}, 0, \ell\right)=$ $\hat{\Pi}_{1}\left(x_{1}^{m}(0, \ell), 0, \ell\right)$. For any $x_{1}^{\prime}<b$, we have $\hat{\Pi}_{1}\left(x_{1}^{\prime}, 1, \ell\right)<\hat{\Pi}_{1}(b, 1, \ell)$, so that, for $\mu^{\prime} \leq 1$, $\hat{\Pi}_{1}\left(x_{1}^{\prime}, \mu^{\prime}, \ell\right)<\hat{\Pi}_{1}(b, 1, \ell)$ and we may conclude that whatever the priors the low cost type would get more profits at $x_{1}^{m}(0, \ell)$ than at $x_{1}^{\prime}$ whatever the posteriors of firm 2 observing $x_{1}^{m}(0, \ell)$. We conclude that the locations within the segment $[0, b)$ cannot be pooling equilibrium locations whatever the priors. Consider now the high cost type. For any location $x_{1}^{\prime}$ within $\left(a, \bar{x}_{1}(1)\right)$, we have $\hat{\Pi}_{1}\left(x_{1}^{\prime}, 1, h\right)<\max _{x_{1}} \hat{\Pi}_{1}\left(x_{1}, 0, h\right)=\hat{\Pi}_{1}\left(x_{1}^{m}(0, h), 0, h\right)$. Hence whatever the priors, the high cost firm 1 would get more profits at $x_{1}^{m}(0, h)$ whatever the posteriors of firm 2 observing $x_{1}^{m}(0, h)$. We conclude that the locations within the segment $\left(a, \bar{x}_{1}(1)\right)$ cannot be pooling equilibrium locations whatever the priors.

Clearly, any location within the segments $[b, a]$ and $\left[\bar{x}_{1}(1), L / 2\right]$ may appear as a pooling equilibrium provided that the prior probability of the low cost type is sufficiently high. Since in most models of competition $x_{1}^{m}(0, h) \neq x_{1}^{m}(0, \ell)$, the lower bound of the prior $\mu$ sustaining any pooling location is strictly positive. It is worthwhile to note that the set of pooling equilibrium locations (for some prior) is larger than the set of the entry preventing locations since within the interval $[b, a]$ the incumbent accommodates entry. In any case, the set of pooling equilibrium locations is not empty since any location preventing entry may appear as a pooling equilibrium 
location provided that the prior probability of the low cost type is sufficiently high.

FIGURE 3

The Perfect Bayesian Equilibria

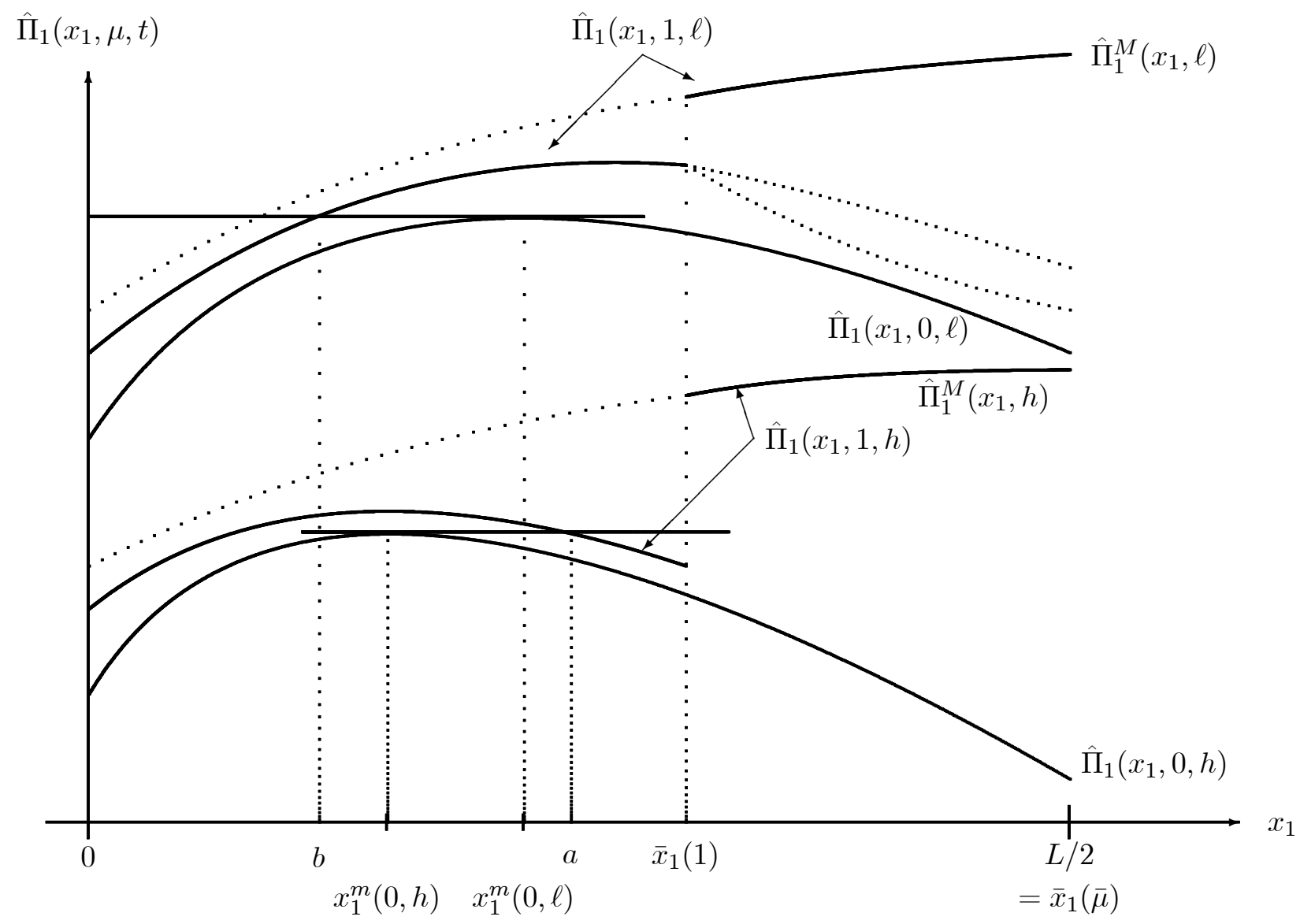

\subsection{Separating equilibria}

In order to understand the conditions under which there exist separating equilibria and why in any one of these equilibria entry is not deterred, consider again Figure 3. Since in a separating equilibrium the incumbent discloses her type, then the equilibrium profit of the high cost type must lie on the $\hat{\Pi}_{1}\left(x_{1}, 0, h\right)$ curve. If so, the unique equilibrium location of the high cost type is $x_{1}^{m}(0, h)$ where $\hat{\Pi}_{1}\left(x_{1}, 0, h\right)$ is maximized. For the same reason, the equilibrium profit of the low cost type must lie on the $\hat{\Pi}_{1}\left(x_{1}, 1, \ell\right)$ curve. But clearly, the low cost type cannot choose any entry deterring location since then the high cost type would mimic the low cost one. The only locations at which the high cost type gets lower profits even if it is wrongly identified as a low cost 
type, are those locations $x_{1}$ within the segment $\left[a, \bar{x}_{1}(1)\right)$ where $\hat{\Pi}_{1}\left(x_{1}, 1, h\right) \leq \hat{\Pi}_{1}\left(x_{1}^{m}(0, h), 0, h\right)$. Thus the low cost firm 1 must choose a location within this interval; if not, the high cost type mimics the low cost type. In order to check if some out-of-equilibrium posteriors sustain such a location $x_{1}^{\prime} \in\left[a, \bar{x}_{1}(1)\right)$ of the low cost type as an equilibrium location, it is sufficient to verify that, for any other location $x_{1}^{\prime \prime} \neq x_{1}^{\prime}$, firm 1 of the low cost type would get lower profits, that is $\hat{\Pi}_{1}\left(x_{1}^{\prime \prime}, 0, \ell\right)<\hat{\Pi}_{1}\left(x_{1}^{\prime}, 1, \ell\right)$, if firm 2 infers that it is competing against the high cost type. It is clearly the case for the reduced profit functions drawn on Figure 3. Note that for $x_{1}^{\prime \prime}=x_{1}^{m}(0, \ell) \neq x_{1}^{\prime}$, then believing that $\mu=0$ is the equilibrium belief to have.

Proposition 2: Suppose that the set $I_{\ell}=\left[a, \bar{x}_{1}(1)\right)$ of locations, for which $\hat{\Pi}_{1}\left(x_{1}, 1, h\right) \leq$ $\hat{\Pi}_{1}\left(x_{1}^{m}(0, h), 0, h\right)$, is not empty, then $x_{1}^{*} \in I_{\ell}$ is a separating equilibrium location for firm 1 of type $\ell$ if and only if for any $x_{1} \neq x_{1}^{*}$ : $\hat{\Pi}_{1}\left(x_{1}, 0, \ell\right) \leq \hat{\Pi}_{1}\left(x_{1}^{*}, 1, \ell\right)$.

Two observations should be stressed. First, the set $I_{\ell}$ may be empty. It would be the case with the $\hat{\Pi}_{1}\left(x_{1}, \mu, h\right)$ curves drawn in Figure 2. Hence in an incomplete information context, the efficient firm 1 can be constrained to pool with the inefficient one. Second and more puzzling, if there exists a separating equilibrium, the efficient firm 1 does not choose a location which deters entry but instead chooses an entry accommodating location although in a complete information context she would choose $x_{1}=L / 2$ and would prevent entry. This is the result of the separating constraint. If the efficient firm 1 were to choose an entry preventing location, the inefficient type would in turn choose the same location, destroying the separating property. In a complete information setting, no such separating constraint is at work.

\subsection{Refinements}

The leeway in updating out-of-equilibrium beliefs gives rise to a plethora of PBE. Let us now employ two standard refinements: the intuitive criterion (Kreps 1984, Cho and Kreps 1987) and D1 (Cho and Kreps 1987, Cho and Sobel 1990), to dismiss the least plausible PBE. Consider an equilibrium $\left\{\left(x_{1}^{*}(t), x_{2}^{*}\left(x_{1}\right), \mu_{t}^{*}\left(x_{1}\right)\right), t=h, \ell\right\}$. Let $\hat{\Pi}_{1}^{*}(t)$ be the equilibrium profit of firm 1 of type $t$ : $\hat{\Pi}_{1}^{*}(t) \equiv \hat{\Pi}_{1}\left(x_{1}^{*}(t), \mu^{*}\left(x_{1}^{*}(t)\right), t\right)$, where for the sake of notational consistency $\mu^{*}\left(x_{1}\right)=$ $\mu_{\ell}^{*}\left(x_{1}\right)$. Suppose that for an out-of-equilibrium location $x_{1}$, the following conditions are satisfied 
where $t \neq t^{\prime}$ :

$$
\begin{aligned}
& \hat{\Pi}_{1}^{*}(t)<\hat{\Pi}_{1}\left(x_{1}, \mu_{t}\left(x_{1}\right)=1, t\right) \\
& \forall \mu \in[0,1], \hat{\Pi}_{1}\left(x_{1}, \mu, t^{\prime}\right)<\hat{\Pi}_{1}^{*}\left(t^{\prime}\right)
\end{aligned}
$$

According to the intuitive criterion, firm 2 observing the out-of-equilibrium location $x_{1}$ should reasonably conclude it is facing a firm 1 of type $t$. Since firm 1 of type $t$ (resp. $t^{\prime}$ ) is earning more (resp. less) at $x_{1}$ when firm 2 is convinced to compete against the type $t$ (resp. whatever firm 2 beliefs) than at the equilibrium location, then firm 1 of type $t$ will spurn the equilibrium and deviate to $x_{1}$. Hence the equilibrium collapses.

The spirit of the D1 criterion is very close to the latter logic. Nevertheless, it meets stronger requirements in the sense that the set of PBE robust to D1 is usually a subset of PBE surviving the intuitive criterion in monotonic signaling games. Therefore we shall apply first the intuitive criterion and thereafter D1 to the remainder of PBE. Recall that, for any location $x_{1}$ and beliefs $\mu$, firm 2 best response location $\tilde{x}_{2}\left(x_{1}, \mu\right)$ is unique. To check the stability of an equilibrium location, suppose that firm 1 of type $t$ deviates from $x_{1}^{*}(t)$ to $x_{1}$. Let $D\left(t \mid x_{1}\right)$ be the set of posterior beliefs $\mu_{t} \in[0,1]$ (with firm 2 responding optimally) that would make the deviation profitable for firm 1. Similarly let the set $D^{0}\left(t \mid x_{1}\right)$ be defined as the subset of posterior beliefs making firm 1 indifferent between switching or not. According to the D1 criterion, firm 2 observing $x_{1}$ should put all the posterior probability on the type $t^{\prime}$ if

$$
D\left(t \mid x_{1}\right) \cup D^{0}\left(t \mid x_{1}\right) \subset D\left(t^{\prime} \mid x_{1}\right) \quad t^{\prime} \neq t
$$

which amounts to say that firm 1 of type $t^{\prime}$ has a stronger incentive to deviate than firm 1 of type $t$.

Let us first consider the separating equilibrium locations. From Proposition 2, we know that firm 1 of type $\ell$ must choose a location in $I_{\ell}$ to be truly identified. It is straightforward to show that the intuitive criterion singles out $a$ (see Figure 3 ) that is the location involving the least cost of separation for the low cost firm 1 . Indeed, take any equilibrium location $x_{1}^{*}(\ell)$ to the right of $a$. If the low cost firm 1 deviates from $x_{1}^{*}(\ell)$ to $d$ (for deviation) in the interval $\left(a, x_{1}^{*}(\ell)\right.$ ), it would get more profits when rightly identified after the deviation than at the equilibrium 
under consideration. Moreover, the high cost firm 1 would get less at $d$ than at its separating equilibrium location $x_{1}^{m}(0, h)$, whatever the posterior belief $\mu$ held by firm 2 after observing the deviation to $d$. Hence firm 2 should reasonably conclude that it is facing a low cost firm 1 . If so, the low cost firm 1 would be better off at $d$ and the equilibrium collapses. For $x_{1}^{*}(\ell)=a$, no such deviation exists: any deviation to a location inside $\left[\bar{x}_{1}(1), L / 2\right]$ allowing the low cost firm 1 to get more than its separating equilibrium profit, would also allow the high cost firm 1 to improve its profit for $\mu$ sufficiently high. The same reasoning applies to any deviation to the left of $a$ allowing the low cost firm 1 to earn more than its equilibrium profits if correctly identified but inducing the high cost firm 1 to deviate also. Thus $a$ is the only equilibrium location robust to the intuitive criterion.

Furthermore, a survives the D1 criterion. The only candidate deviations of interest are those which would induce firm 2 to believe it is competing against the low cost firm 1. But, as a consequence of the single crossing property mentioned in Section 2, for any deviation $d$ and any belief $\mu$ such that $\hat{\Pi}_{1}^{*}(h)=\hat{\Pi}_{1}(d, \mu, h)$, we have $D(\ell \mid d) \cup D^{0}(\ell \mid d) \subset D(h \mid d)$ (see Boyer, Laffont, Mahenc and Moreaux 1995) and thus such a deviation would induce firm 2 to infer, according to D1, that it is facing the high cost firm 1 and not the low cost firm 1: hence neither wishes to deviate and $a$ is a D1 separating equilibrium location for the low cost firm 1.

Let us now turn to the pooling equilibrium locations. Recall that, in such an equilibrium, both types of firm 1 may either accommodate entry with a location inside $[b, a]$ or deter entry with a location inside $\left[\bar{x}_{1}(1), L / 2\right]$. We show first that locations in $[b, a]$ robust to the intuitive criterion don't survive D1. Consider such a location $x_{1}^{*}$ based on the prior $\mu_{0}$. Suppose there exists a deviation $d \in\left(x_{1}^{*}, \bar{x}_{1}(1)\right)$ as illustrated on Figure 4 such that firm 1 of type $h$ would strictly prefer $d$ to $x_{1}^{*}$ if by deviating it would be thought to be of the low-cost type for sure, that is $\hat{\Pi}_{1}^{*}(\ell)<\hat{\Pi}_{1}(d, 1, l)$, while firm 1 of type $\ell$ would rather stick to $x_{1}^{*}$ and be interpreted as of type $\ell$ with probability $\mu_{0}$ than choose $d$, no matter what inferences firm 2 might draw from the observation of $d$, that is $\hat{\Pi}_{1}(d, \mu, h)<\hat{\Pi}_{1}^{*}(h)$ whatever $\mu$. 
FIGURE 4

The Refinement Criteria

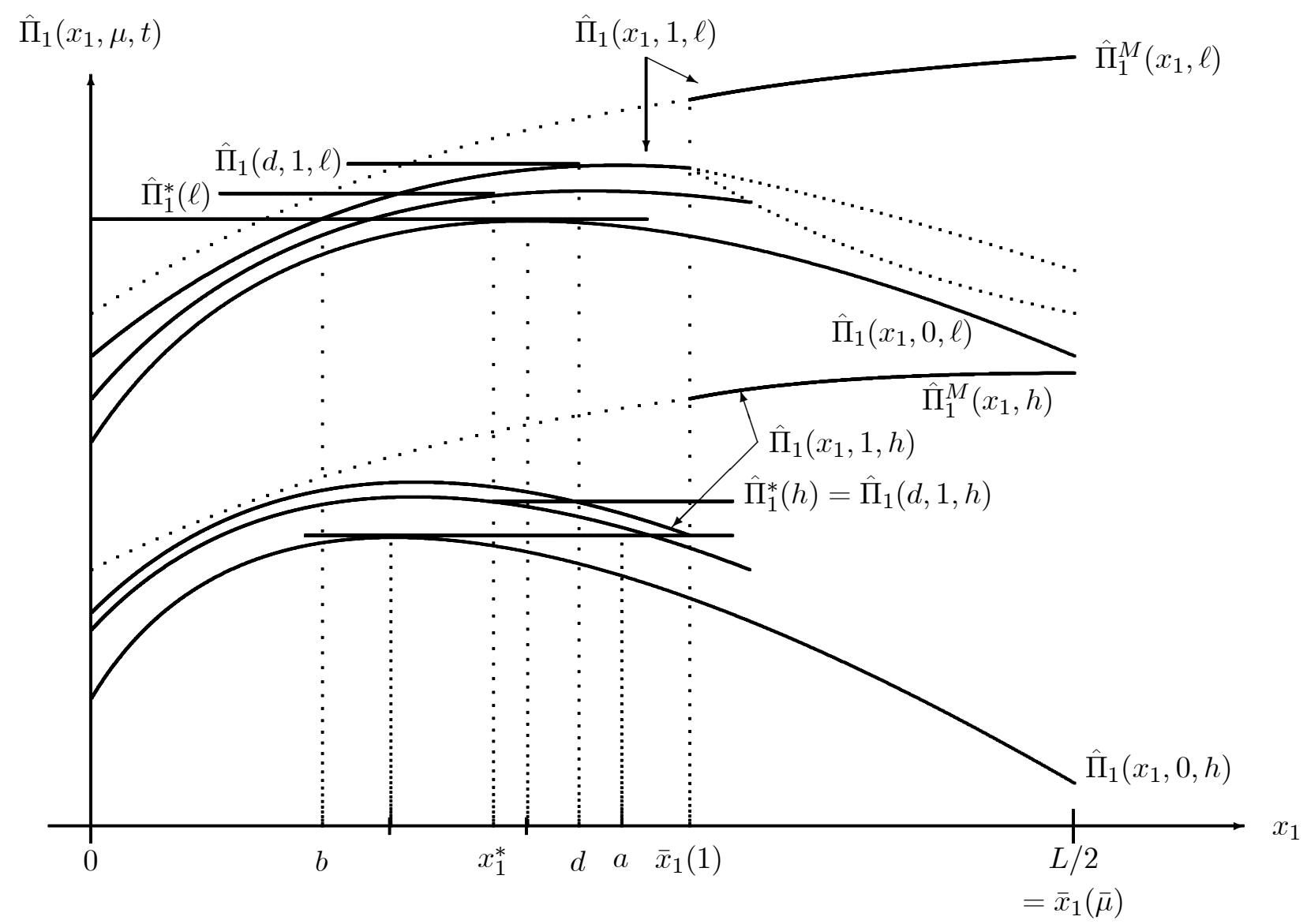

According to the intuitive criterion, firm 2, when observing $d$, should infer that its competitor is of the low-cost type so the latter could then profitably separate itself. As a result, the pooling equilibrium location considered is eliminated by the intuitive criterion. When $a<\bar{x}_{1}(1)$, as it is the case in Figure 4, such a deviation exists for all entry accommodating pooling locations and none survives the intuitive criterion. Otherwise the functions $\hat{\Pi}_{1}\left(x_{1}, \mu, h\right)$ are those depicted in Figure 2 and a deviation $d$ meeting the requirements mentioned above can be found inside $\left(x_{1}^{*}, \bar{x}_{1}(1)\right)$ provided that the prior $\mu_{0}$ is such that $\hat{\Pi}_{1}^{*}(h)>\lim _{x_{1} \rightarrow \bar{x}_{1}(1)} \hat{\Pi}_{1}\left(x_{1}, 1, l\right)$. For lower values of $\mu_{0}$, there exist entry deterring limit locations, namely $\bar{x}_{1}\left(\mu_{0}\right)$ if $\mu_{0}>\bar{\mu}$ and $L / 2$ if $\mu_{0} \leq \bar{\mu}$. In both cases, the intuitive criterion fails to eliminate those locations because, when $\mu_{0}>\bar{\mu}$, any deviation giving the low-cost firm 1 more than $\hat{\Pi}_{1}^{*}(\ell)$ if rightly identified would also give the high-cost firm 1 more than $\hat{\Pi}_{1}^{*}(h)$, and when $\mu_{0} \leq \bar{\mu}$, there is no deviation giving the 
low-cost firm 1 more than $\hat{\Pi}_{1}^{*}(\ell)$ if rightly identified.

However, applying D1 to both of these cases succeeds in making them implausible. Indeed, consider a deviation $d \in\left(x_{1}^{*}, \bar{x}_{1}\left(\max \left(\mu_{0}, \bar{\mu}\right)\right)\right)$. Building on the model without entry investigated in Boyer, Laffont, Mahenc and Moreaux (1995), it can be shown that, for any belief $\mu$ held after observing $d$ such that $\hat{\Pi}_{1}^{*}(h)=\hat{\Pi}_{1}(d, \mu, h)$, firm 1 of type $\ell$ has a stronger incentive to deviate, that is $D(h \mid d) \cup D^{0}(h \mid d) \subset D(\ell \mid d)$. Thus firm 2 observing $d$ should infer that it is a move by the low-cost type. If moreover $d$ is close enough to $x_{1}^{*}$, then $\hat{\Pi}_{1}^{*}(t)<\hat{\Pi}_{1}(d, 1, t)$ for $t=h, \ell$, and both types will deviate.

Unlike the entry accommodating locations, the entry deterring locations survive both the intuitive criterion and D1. Consider an entry deterring pooling location $x_{1}^{*}$. For any deviation $d<x_{1}^{*}$, both types of firm 1 earn less than their equilibrium profit no matter what beliefs might be held by firm 2 upon observing the deviation. For deviations $d>x_{1}^{*}$, the posteriors $\mu$ are either high enough for both types to deter entry and earn more than their equilibrium profit, or low enough for both types to accommodate entry and earn less than their equilibrium profit. Therefore both the intuitive criterion and D1 fail to impose a restriction on these posteriors that could induce the deviation.

To sum up:

Proposition 3: The only separating equilibrium robust to the intuitive and D1 criteria is the equilibrium implying the least separating penalty for the low cost firm 1 . The only pooling equilibria robust to the D1 criterion are the entry deterring equilibria.

\section{THE UNIFORM MILL PRICING CASE}

We review in this section Hotelling's (1929) model of spatial competition in the light of our findings. ${ }^{9}$ With consumers uniformly distributed along the line $[0, L]$ and transportation costs assumed quadratic with respect to distance $k d^{2}$, D'Aspremont, Gabszewicz and Thisse (1979) showed the existence of a price equilibrium for any given locations $\left(x_{1}, x_{2}\right)$ of the two firms. The

\footnotetext{
${ }^{9}$ The discussion is willingly intuitive rather than rigorous and the reader is referred to Boyer, Mahenc and Moreaux (2001) for a thorough analysis.
} 
analysis of the second-stage competition shows that firm 2, if it enters the market, locates as far as possible from the market center whatever the incumbent's type. Hence $\tilde{x}_{2}\left(x_{1}, \mu\right)=L$ for any value of the pair $\left(x_{1}, \mu\right)$ accommodating entry. The profit function of the incumbent is therefore also independent of $\mu$ when firm 2 enters. If $\mu$ is such that firm 2 chooses to stay out, then firm 1 enjoys a monopoly position. Therefore, all the $\hat{\Pi}_{1}\left(x_{1}, \mu, t\right)$ functions in Figure 2 collapse to one function; if $\mu>\bar{\mu}$, the function is discontinuous at $\bar{x}_{1}(\mu)$.

\subsection{The separating location equilibria}

In a separating equilibrium, we have $x_{1}^{* h} \neq x_{1}^{* \ell}$. The location chosen by the high-cost type is $x_{1}^{m}(0, h)=0$ since $\partial \Pi_{1}\left(x_{1}, x_{2}, h\right) / \partial x_{1}$ is negative. Moreover since $\Pi_{1}\left(x_{1}, \mu, t\right)$ is independent of $\mu$, the low-cost type necessarily locates at $x_{1}^{m}(1, \ell)$. Provided that $x_{1}^{m}(1, \ell)$ is different from $x_{1}^{m}(0, h)=0$, if the differential production cost $c$ is large enough, then we have a separating equilibrium; otherwise separation of both types is impossible and they both choose to locate at 0.

As already shown in the general framework, the low-cost incumbent must accommodate entry in order to be perfectly identified by her competitor. Obviously such a strategy is costly for the low-cost incumbent who loses her complete information monopoly position at the market center (the market center is not a separating equilibrium). However her forgone profit at $x_{1}^{m}(1, \ell)$ is less than the loss the high-cost type would incur by moving from $x_{1}^{m}(0, h)=0$ to $x_{1}^{m}(1, \ell)$, thus mimicry is prevented. ${ }^{10}$

The location pair $\left(x_{1}^{m}(0, h)=0, x_{1}^{m}(1, \ell)>0\right)$ constitutes the unique separating equilibrium in this particular case contrary to our general results which show that in general there is a multiplicity of separating equilibrium locations whenever there exists one. The reason of uniqueness in the case of uniform mill pricing stems from the fact that beliefs have no effect on product differentiation once the decision to enter has been taken since the entrant is better off locating as far apart as possible whatever his belief. This precludes any incentive for the high-cost incumbent to switch from her separating equilibrium location $x_{1}^{m}(0, h)$ to any location $x_{1}$ outside the

\footnotetext{
${ }^{10}$ Technically, the interval $\left(a, \bar{x}_{1}(1)\right)$ of separating location candidates for the low-cost type is now given by $\left(0, \bar{x}_{1}(1)\right)$ but there are no out-of-equilibrium posteriors beliefs to support any of those separating location candidates by the low-cost incumbent besides $x_{1}^{m}(1, \ell)$.
} 
interval $\left[\bar{x}_{1}(1), L / 2\right]$, even if she is then perceived to be of the low-cost type. Therefore, when trying to signal her type, the low-cost incumbent is free to locate anywhere outside $\left[\bar{x}_{1}(1), L / 2\right]$.

\subsection{The pooling location equilibria}

As we showed in the general framework, any location $x_{1}^{*}$ inside $\left[\bar{x}_{1}(1), L / 2\right]$ together with $\mu^{0} \geq$ $\bar{\mu}\left(x_{1}^{*}\right)$ is a pooling equilibrium. This kind of pooling equilibria prevents entry because the potential entrant's prior belief is sufficiently optimistic for the high-cost type to trick him with a location in the neighborhood of the market center.

There also exists in the present case a pooling equilibrium where both types accommodate entry, namely $x_{1}^{m}(0, t)$. It is the only candidate for a pooling equilibrium provided that $x_{1}^{m}(0, \ell)=$ $x_{1}^{m}(0, h)=0$ a case which is obtained if the differential cost $c$ is large enough. It is straightforward to show that $x_{1}^{*}=0$ is supported as a pooling equilibrium by the posterior belief function:

$$
\mu_{\ell}^{*}\left(x_{1}\right)\left\{\begin{array}{lll}
\leq & \bar{\mu}\left(x_{1}\right) & \text { for } x_{1} \in\left(\bar{x}_{1}(1), L / 2\right) \\
= & \mu_{\ell}^{0} & \text { for } x_{1}=x_{1}^{*} \\
\text { arbitrary } & \text { otherwise } &
\end{array}\right.
$$

The intuitions for these results have already been developed in the general framework. Surprisingly enough, the entry accommodating pooling equilibrium location is unique. Note that this pooling equilibrium exists for values of the cost differential $c$ for which there is no separating equilibrium location. The reason why it is unique is basically the same as the reason for the uniqueness of the separating equilibrium: for any $t$ and whatever $\mu^{0} \in[0,1], x_{1}^{m}\left(\mu_{\ell}^{0}, t\right)=0$ is the only entry accommodating location that Pareto-dominates any other entry accommodating location in which the incumbent would be taken for sure as the low-cost type and thus no deviation is profitable whatever the posterior belief following this deviation. In other words, if $x_{1}^{m}(0, t)=0$ for all $t$, the incumbent of type $t$ is better off locating at $x_{1}^{m}(0, t)$ than at any entry accommodating location different from 0 with any prior $\mu^{0} \in[0,1]$. 


\section{THE DELIVERED PRICING CASE}

We consider again the same basic model but allow firms to price discriminate, that is, to compete in delivered prices in the second stage of the game as in Hoover (1937), Hurter and Lederer (1985) and Lederer and Hurter (1986). With consumers uniformly distributed on the market segment and linear transportation costs, we assume that an incumbent of any type, whatever her location, could supply any consumer and make a profit over variable costs (production + transportation) were she in a monopoly position. We also assume that firm 2 can always find a location so as to enjoy a positive share of the market and a positive profit gross of the fixed sunk cost of entry, provided that firm 1 does not sell at prices lower than its total variable cost. The second stage competition is assumed to be a Bertrand-like competition in delivered price schedules. In this way, the existence of an equilibrium in pure strategies is guaranteed for any location pair $\left(x_{1}, x_{2}\right) .{ }^{11}$ As before, provided that the fixed sunk cost of entry falls within the proper interval and that the differential operating cost $c$ is not too large, there are locations in the neighborhood of the market center which, if chosen by the incumbent, deter entry when the posterior probability $\mu$ is larger than some level, and also locations which, if chosen by the incumbent, accommodate entry.

It turns out that the profit function $\hat{\Pi}_{1}\left(x_{1}, \mu, t\right)$, unlike those in the uniform mill pricing case, are parabolic and single peaked over the interval $\left[0, \bar{x}_{1}(\mu)\right) .{ }^{12}$ Moreover, given a location in this interval, the higher $\mu$ the higher the profit level $\hat{\Pi}_{1}\left(x_{1}, \mu, t\right)$ since firm 2's best response when entry is accommodated strictly increases with $\mu$. This is to be contrasted with the mill pricing case where firm 2's optimal location is at the right end of the market whatever its belief regarding firm 1's type. A straightforward consequence is that the locations $x_{1}^{m}(\mu, t)$ in the delivered pricing case are not the same with respect to $\mu$; hence the existence of multiple entry accommodating equilibria, either separating or pooling, may be expected contrary to the uniqueness result in the uniform mill pricing case.

\footnotetext{
${ }^{11}$ Existence and uniqueness of the price equilibrium hold for any location pair with increasing transportation cost functions (see Thisse and Vives (1988))

${ }^{12}$ Again, see Boyer, Mahenc and Moreaux (2001) for a thorough analysis.
} 


\subsection{The separating location equilibria}

Our general results on separating equilibria stated in Proposition 2 can be directly applied in the delivered pricing case. Indeed, the set $I_{\ell}$ is not empty provided that $f$ and $c$ are not too large and any location $x_{1}^{\prime}$ in this set can be supported as a separating location equilibrium for firm 1 of type $\ell$ provided that posterior probabilities lead to $\hat{\Pi}_{1}\left(x_{1}^{\prime \prime}, 0, \ell\right)<\hat{\Pi}_{1}\left(x_{1}^{\prime}, 1, \ell\right)$.

\subsection{The pooling location equilibria}

Two kinds of pooling equilibrium locations emerge: a continuum of locations in the neighborhood of the market center that deter entry and a continuum of locations away from the market center that accommodate entry.

The intuition for the existence of entry deterring pooling locations is basically the same as in the uniform mill pricing case. First, if the incumbent's reputation is a priori good, that is $\mu^{0}$ is rather high, then the low-cost incumbent is expected to locate in equilibrium at the market center or close to it. Therefore, there is an opportunity for the high-cost incumbent to mimic her low-cost counterpart and move in the neighborhood of the market center, be perceived as an efficient incumbent, deter entry and act as a monopoly. Thus, whatever the true cost of the incumbent, there is no entry in this case whereas under complete information entry occurs with probability $1-\mu^{0}$. The potential entrant is not really fooled but cannot learn the true cost characteristic of his competitor because he expects her to rather be of the high-cost type. Consider for instance the equilibrium at the market center and suppose that the potential entrant takes the incumbent to be of the high-cost type for sure if he observes a location different from the market center. Then both incumbent types are obviously better off at the market center and their equilibrium behavior does not permit the identification of their true cost characteristic. The potential entrant knows that and the incumbent knows that he knows, hence she rationally anticipates her competitor not to enter if he observes her at the market center.

Regarding the entry accommodating pooling locations, the main difference with the uniform mill pricing case is the multiplicity of equilibria in the delivered pricing case. Remember that in the previous case, the entrant's beliefs has no impact on product differentiation once the 
decision to enter the market has been taken. However in the present case the entrant's belief does matter: the entrant differentiates more his product when he believes the incumbent to rather be of the low-cost type.

\section{CONCLUSION}

Previous works have emphasized that product location may be used as an entry-deterring device in horizontally differentiated markets. We contribute to this literature by showing that information plays a crucial role in the emergence of limit location strategies preventing entry.

If the potential entrant is not perfectly informed about the incumbent's costs, pre-entry product specification may rationally be read as a signal regarding these costs. Hence, beliefs are relevant in the emergence of entry deterring strategies. We have considered a market which under full information would be monopolized by a low-cost incumbent capable of blockading entry by locating at the market center, but would not be monopolized by a high-cost incumbent. Under incomplete information, if the potential entrant expects a priori the incumbent to be of the low cost type, the market center becomes a plausible location from which a high cost incumbent blockades entry. On the other hand, if the entrant expects a priori the incumbent to be a high cost type with a high probability, entry will occur regardless of the incumbent's cost. The low cost incumbent then finds it more profitable to abandon her full information location at the market center and to accommodate entry. She moves away from the market center in order to either find a location where she can credibly disclose information on her true costs, or, if mimicry from a high cost incumbent cannot be prevented, relax price competition through more product differentiation. 


\section{References}

[1] ANDERSON, S.P. (1987), "Spatial Competition and Price Leadership", International Journal of Industrial Organization, 5 , 369-398.

[2] ANDERSON, S.P., A. DE PALMA and J.F. THISSE (1992), Discrete Choice Theory of Product Differentiation, Cambridge, Mass.: MIT Press.

[3] BAGWELL, K. and G. RAMEY (1988)," Advertising and Limit Pricing", Rand Journal of Economics, 19, 59-71.

[4] BAIN, J.S. (1956), Barriers to New Competition, Cambridge, Mass.: Harvard University Press.

[5] BESTER, H. (1992), "Bertrand Equilibrium in a Differentiated Duopoly", International Economic Review, 33, 433-448.

[6] BOnAnnO, G. (1985), "Product Proliferation and Entry Deterrence Revisited", STICERD - Discussion Paper n¹14, London School of Economics.

[7] BONANNO, G. (1987), "Location Choice, Product Proliferation and Entry Deterrence", Review of Economic Studies, 54, 37-45.

[8] BOYER, M., J.J. LAFFONT, P. MAHENC and M. MOREAUX (1994), "Location Distortions under Incomplete Information", Regional Science and Urban Economics, 24, 409-440.

[9] BOYER, M., J.J. LAFFONT, P. MAHENC and M. MOREAUX (1995), "Sequential Location Equilibria under Incomplete Information", Economic Theory, 6, 323-350.

[10] BOYER, M., P. MAHENC and M. MOREAUX (2001), "Location Equilibria and Entry Prevention under Incomplete Information", mimeo, JEREM, Université de Perpignan.

[11] CHAMPSAUR, P. and J.C. ROCHET, "Existence of a Price Equilibrium in a Differentiated Industry", Discussion Paper nº801, INSEE Paris, 1988.

[12] CHO, I.K. and D.M. KREPS (1987), "Signaling Game and Stable Equilibria", Quarterly Journal of Economics, 102, 179-221. 
[13] CHO, I.K. and J. SOBEL (1990), "Strategic Stability and Uniqueness in Signaling Games", Journal of Economic Theory, 50, 381-413.

[14] D'ASPREMONT, C., J.J. GABSZEWICZ and J.F. THISSE (1979), "On Hotelling Stability in Competition", Econometrica, 47, 1145-1150.

[15] DIXIT, A. (1979), "A Model of Duopoly Suggesting a Theory of Entry Barriers", Bell Journal of Economics, 10, 20-32.

[16] DONNENFELD, S. and S. WEBER (1995), "Limit Qualities and Entry Deterrence", Rand Journal of Economics, 26, 113-130.

[17] EATON, C.B. and R.G. LIPSEY (1989), "Product Differentiation", in R. Schmalensee and R. Willig (eds), Handbook of Industrial Organization, Vol. I, Amsterdam, North-Holland.

[18] FRIEDMAN, J. (1979), "On Entry Preventing Behavior", in S.J. Brams, A. Schotter and G. Schwodiauer (eds), Applied Game Theory, Vienna, Physica-Verlag.

[19] HARRINGTON, J.E., Jr.(1987), "Oligopolistic Entry Deterrence under Incomplete Information", Rand Journal of Economics, 18, 211-231.

[20] HOOVER, E.M. (1937), "Spatial Price Discrimination", Review of Economic Studies, 4, 182-191.

[21] HOTELliNG, M. (1929), "Stability in Competition", Economic Journal, 39, 41-57.

[22] HURTER, A.P. and P.J. LEDERER (1985), "Spatial Duopoly with Discriminatory Pricing", Regional Science and Urban Economics, 15, 541-553.

[23] KREPS, D.M. (1984), "Signaling Games and Stable Equilibria", mimeo, Graduate School of Business, Stanford University.

[24] JUDD, K.L. (1985), "Credible Spatial Preemption", Rand Journal of Economics, 16, 153166.

[25] LEDERER, P.J. and A.P. HURTER (1986), "Competition of Firms: Discriminatory Pricing and Location", Econometrica, 54, 623-640. 
[26] MILGROM, P. and J. ROBERTS (1982), "Limit Pricing and Entry under Incomplete Information", Econometrica, 50, 443-460.

[27] OVERGAARD, P. B. (1994), "Equilibrium Effects of Potential Entry when Prices Signal Quality", European Economic Review, 38, 367-383.

[28] SCHMALENSEE, R. (1978), "Entry Deterrence in the Ready-to-eat Breakfast Cereal Industry", Bell Journal of Economics, 9, 305-327.

[29] SMILEY, R. (1988), "Empirical Evidence on Strategic Entry Deterrence", International Journal of Idustrial Organization, 6 , 167-180.

[30] SPENCE, A.M. (1977), "Entry, Investment, and Oligopolistic Pricing", Bell Journal of Economics, 8, 534-544.

[31] THISSE, J.-F. and X. VIVES (1988), "On the Strategic Choice of Spatial Price, American Economic Review, 78, 122-137.

[32] WENDERS, J.T. (1971), "Excess Capacity as a Barrier to Entry", Journal of Industrial Economics, 20, 14-19.

[33] ZISS, S. (1993), "Entry Deterrence, Cost Advantage and Product Differentiation", Regional Science and Urban Economics, 23, 523-543. 


\section{Liste des publications au CIRANO*}

Série Scientifique / Scientific Series (ISSN 1198-8177)

2002s-15 Entry Preventing Locations Under Incomplete Information / Marcel Boyer, Philippe Mahenc et Michel Moreaux

2002s-14 On the Relationship Between Financial Status and Investment in Technological Flexibility / Marcel Boyer, Armel Jacques et Michel Moreaux

2002s-13 Modeling the Choice Between Regulation and Liability in Terms of Social Welfare / Marcel Boyer et Donatella Porrini

2002s-12 Observation, Flexibilité et Structures Technologiques des Industries / Marcel Boyer, Armel Jacques et Michel Moreaux

2002s-11 Idiosyncratic Consumption Risk and the Cross-Section of Asset Returns / Kris Jacobs et Kevin Q. Wang

2002s-10 The Demand for the Arts / Louis Lévy-Garboua et Claude Montmarquette

2002s-09 Relative Wealth, Status Seeking, and Catching Up / Ngo Van Long, Koji Shimomura

2002s-08 The Rate of Risk Aversion May Be Lower Than You Think / Kris Jacobs

2002s-07 A Structural Analysis of the Correlated Random Coefficient Wage Regression Model / Christian Belzil et Jörgen Hansen

2002s-06 Information Asymmetry, Insurance, and the Decision to Hospitalize / Åke Blomqvist et Pierre Thomas Léger

2002s-05 Coping with Stressful Decisions: Individual Differences, Appraisals and Choice / Ann-Renée Blais

2002s-04 A New Proof Of The Maximum Principle / Ngo Van Long et Koji Shimomura

2002s-03 Macro Surprises And Short-Term Behaviour In Bond Futures / Eugene Durenard et David Veredas

2002s-02 Financial Asset Returns, Market Timing, and Volatility Dynamics / Peter F. Christoffersen et Francis X. Diebold

2002s-01 An Empirical Analysis of Water Supply Contracts / Serge Garcia et Alban Thomas

2001s-71 A Theoretical Comparison Between Integrated and Realized Volatilities Modeling / Nour Meddahi

2001s-70 An Eigenfunction Approach for Volatility Modeling / Nour Meddahi

2001s-69 Dynamic Prevention in Short Term Insurance Contracts / M. Martin Boyer et Karine Gobert

2001s-68 Serial Cost Sharing in Multidimensional Contexts / Cyril Téjédo et Michel Truchon

2001s-67 Learning from Strike / Fabienne Tournadre et Marie-Claire Villeval

2001s-66 Incentives in Common Agency / Bernard Sinclair-Desgagné

* Consultez la liste complète des publications du CIRANO et les publications elles-mêmes sur notre site Internet : 
2001s-65 Detecting Mutiple Breaks in Financial Market Volatility Dynamics / Elena Andreou et Eric Ghysels

2001s-64 Real Options, Preemption, and the Dynamics of Industry Investments / Marcel Boyer, Pierre Lasserre, Thomas Mariotti et Michel Moreaux

2001s-63 Dropout, School Performance and Working while in School: An Econometric Model with Heterogeneous Groups / Marcel Dagenais, Claude Montmarquette et Nathalie Viennot-Briot

2001s-62 Derivatives Do Affect Mutual Funds Returns : How and When? / Charles Cao, Eric Ghysels et Frank Hatheway

2001s-61 Conditional Quantiles of Volatility in Equity Index and Foreign Exchange Data / John W. Galbraith, Serguei Zernov and Victoria Zinde-Walsh

2001s-60 The Public-Private Sector Risk-Sharing in the French Insurance "Cat. Nat. System" / Nathalie de Marcellis-Warin et Erwann Michel-Kerjan

2001s-59 Compensation and Auditing with Correlated Information / M. Martin Boyer et Patrick González

2001s-58 Resistance is Futile: An Essay in Crime and Commitment / M. Martin Boyer

2001s-57 The Unreliability of Output Gap Estimates in Real Time / Athanasios Orphanides et Simon van Norden

2001s-56 Exact Nonparametric Two-Sample Homogeneity Tests for Possibly Discrete Distributions / Jean-Marie Dufour et Abdeljelil Farhat

2001s-55 Les coûts de la réglementation : une revue de la littérature / Robert Gagné, Paul Lanoie, Pierre-Carl Micheud et Michel Patry

2001s-54 Testing for structural Change in the Presence of Auxiliary Models / Eric Ghysels et Alain Guay

2001s-53 Environmental Regulation and Productivity: New Findings on the Porter Hypothesis / Paul Lanoie, Michel Patry et Richard Lajeunesse

2001s-52 The Aftermarket Performance of Initial Public Offerings in Canada / Maher Kooli et Jean-Marc Suret

2001s-51 Capital Structure and Risk Management / Karine Gobert

2001s-50 The Underpricing of Initial Public Offerings: Futher Canadian Evidence / Maher Kooli et Jean-Marc Suret

2001s-49 How Innovative Are Canadian Firms Compared to Some European Firms? A Comparative Look at Innovation Surveys / Pierre Mohnen et Pierre Therrien

2001s-48 A Tale of Two Ports / Ngo Van Long et Kar-yiu Wong

2001s-47 Wage Policy of Firms: An Empirical Investigation / Stéphanie Lluis

2001s-46 Forecasting Some Low-Predictability Time Series Using Diffusion Indices / Marc Brisson, Bryan Campbell et John W. Galbraith

2001s-45 The Importance of the Loss Function in Option Pricing / Peter Christoffersen et Kris Jacobs

2001s-44 Let's Get "Real" about Using Economic Data / Peter Christoffersen, Eric Ghysels et Norman R. Swanson

2001s-43 Fragmentation, Outsourcing and the Service Sector / Ngo Van Long, Ray Riezman et Antoine Soubeyran 